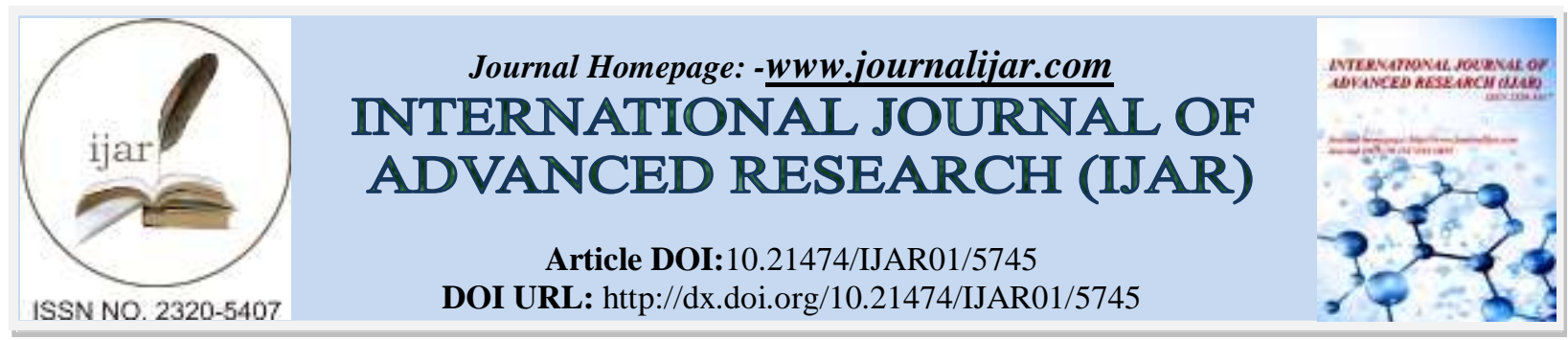

RESEARCH ARTICLE

\title{
MINI - RETROMANDIBULAR APPROACH FOR OPEN REDUCTION AND INTERNAL FIXATION OF CONDYLAR FRACTURES BY DELTA PLATES: AN EXPLORATORY STUDY.
}

\author{
Dr. Sujeeth Kumar Shetty, Mds, Dr. Vijay Singh Rai, Mds, Dr. Sai Krishna D., Mds, Dr. Asutosh Das, Mds \\ and Dr. Praveen Kumar Singh, Mds.
}

\section{Manuscript Info}

Manuscript History

Received: 02 September 2017

Final Accepted: 04 October 2017

Published: November 2017

Key words:-

Mini retromandibular approach.Delta condylar plates.Condylar fracture.

\begin{abstract}
Background: The main objective of our study is to evaluate the new delta condylar plate for condylar fracture with mini retromandibular approach.

Materials and methods: 20 patients with displaced condylar fracture were treated with delta condylar plate using mini retromandibular approach. Patients were evaluated on the basis of pre op and post op parameters and X-rays. Patients were followed for 18 months.

Results: In 20 patients, there was high male predominance (75\%) to female $(25 \%)$. The mean mouth opening is $44.85 \mathrm{~mm}(40-50 \mathrm{~mm})$. The duration of surgery varied from minimum of 40 min to maximum of 65 $\min ($ mean $=52.95 \mathrm{~min})$. In this study excellent access was achieved in 14 cases $(70 \%)$, access was good in 5 cases $(25 \%)$ \& fair in 1 case $(5 \%)$. Post operative complications like infection at surgical site $(25 \%)$ is in 5 cases \&sialocele (15\%) in 3 case. We didn't encounter any facial nerve palsy. All 20 patients (100\%) had inconspicuous scar which was well camouflaged.

Conclusion: The mini retromandibular approach is easy and fast to perform and carries low risk of damaging the facial nerve while leaving a barely noticeable scar. Delta shaped plate for condylar fractures aids in neutralization of changing strains and the plate can be easily place at the constricted condylar neck region. We concluded that surgical treatment of the fractured, displaced condyle using the mini retromandibular approach for anatomic reduction using delta condylar plates is excellent.
\end{abstract}

Copy Right, IJAR, 2017,. All rights reserved.

\section{Introduction:-}

Trauma is a major health and social issue in the World. Every year people of all ages sustain facial injuries from automobile and other vehicular collisions, firearms, athletic activities, or altercations. Many of these injuries have maxillofacial fractures such as fractures of the lower jaw, upper jaw, palate, cheekbones, nose, bone surrounding the eyes, skull, injuries to the teeth or combination injuries.[1]

With an incidence rate of $36 \%$ to $70 \%$, mandibular fracture is the most common fracture of the maxillofacial complex.[2] The temporomandibular region is certainly not exempt from injury. Among mandibular fractures, 
mandibular condylar fractures represents $26 \%$ to $57 \%$ of all mandibular fractures[3]. The complexity of this region and its anatomic proximity to other craniofacial structures make diagnosis and treatment especially challenging.[4]

For decades, moderately displaced condylar fracture have been treated with closed reduction consisting of inter maxillary fixation followed by physiotherapy. Conservative treatment is easier and less invasive with no surgical complications. Consequently, several publications have emphasized the acceptable functional results of conservative treatment in contrast to the risks of surgery.[5]

Long-term follow up studies on condylar fractures treated conservatively have shown that growth disturbances or dysfunction of the masticatory system in young people. In meta analysis study conducted by Essam Ahmed and Edward Ellis in 2014, they confirmed that open and internal fixation of condylar fractures have superior functional clinical outcome subjectively and objectively in comparison to conservative management.

Among the various approaches for open reduction and internal fixation of the condylar fracture, retromandibular approach is easier and safer than submandibular approach \& the access is much more superior when compared to the preauricularapproach[6]. The only disadvantage is a noticeable scar. To eliminate the scar we used mini retromandibular approach which is $20 \mathrm{~mm}$ in length in comparison to $30-40 \mathrm{~mm}$ in retromandibular incision. Incision is given posterior to the ramus of mandible and $1 \mathrm{~cm}$ caudal to the radix of the auricular lobule.[7]

Different kinds of fixation methods have been used for condylar fractures such as wires, pins, screws, and plates. Fixation with rigidminiplates provides more stability than transosseous wiring. The miniplate system available today facilitates fragment fixation, although bone resorption in connection with miniplates has been reported[8].

Single miniplate fixation is adequate if the fragments are aligned properly. If functional forces actually exceed the rigidity of one miniplate, then the use of two has been proposed. Alternatively, a single $2.4 \mathrm{~mm}$ plate or a single 2.0 $\mathrm{mm}$ mini-dynamic compression plate may be used for fixation of condylar fractures, as they offer more resistance to rotation and 3-point bending. However, in the condylar fractures, the amount of bone is not always adequate to permit placement of $2-3$ screws per fragment.

To overcome this problem, various plate designs have been put forward such as L shape, Y shape, or 3-D plate for condylar fractures, which helps in neutralization of the stress patterns at the condylar region[9]. Delta condylar plate is a 3-D plate, shaped for adaptation in the anatomically constricted region of condylar region. The Delta plate is triangular shape with thickness of $1 \mathrm{~mm}$ and a length of $20 \mathrm{~mm}$. The plate is $5 \mathrm{~mm}$ broad at the top and $12 \mathrm{~mm}$ at the bottom. The two horizontally placed holes are present at the base of the plate.(Figure 1). Due to its small triangular shape design, the plate can be more easily be placed on the condylar process than the double-plate and at the same time ensures a stable and functional osteosynthesis[10].

So in the study we have evaluated the use of delta plate for condylar fracture with mini retromandibular approach.

\section{Material and Methods:-}

Twenty patients who have $\mathrm{U} / \mathrm{L}$ or $\mathrm{B} / \mathrm{L}$ condylar fractures with associated mid face fractures were randomly selected for open reduction and internal fixation from Department of Oral and Maxillofacial Surgery, J. S. S. Dental College \& Hospital, Mysore, Dental Out Patient Department, J. S. S. Medical College \& Hospital, Mysore from 2015 2016.

\section{Inclusion Criteria:-}

1. Adult patients of age $18-55$ years both sexes

2. Bilateral or unilateral condylar fractures with associated mid face fractures

3. Condylar fractures with occlusal derangement

4. Condylar fractures with functional interference

5. Patients who cannot tolerate IMF for long duration

\section{Exclusion Criteria:-}

1. Patients who have undergone previous surgery or trauma in the proposed surgical site.

2. Patients who have familial tendency to form hypertrophic scar.

3. Patients with structural deficits of condyle. 
4. Patients with history of pathology in pericondylar region.

5. Patients with systemic bone diseases.

All the subjects received intravenous antibiotics from the time of admission until discharge. Following this, 5-day course of oral antibiotics is prescribed. We follow a regular protocol which includes pre-surgical evaluation of the patient, diagnosis of the fracture (OPG,PA view mandible)(Figure 2) routine blood investigations and treatment plan. Following initial preparation procedure, clinical parameters and radiographic findings were recorded followed by open reduction and internal fixation using Delta Titanium condylar plates via mini retromandibular approach under general anaesthesia. Relevant clinical parameters were assessed preoperatively, intraoperatively \& postoperatively, followed by weekly follow up for six weeks.

\section{Surgical Technique:-}

After skin preparation \& draping the site, local infiltration of $2 \%$ xylocaine with adrenaline was given after marking the incision line. Incision of length $2 \mathrm{~cm}$ is made in a natural crease of the neck beginning from $1 \mathrm{~cm}$ under the mastoid apex and running parallel to the anterior aspect of the sternocleidomastoid muscle. After dissecting through the skin, subcutaneous fat and platysma, the SMAS and underlying parotid fascia were identified and incised parallel and $5.0 \mathrm{~mm}$ anterior to the posterior rim of the ramus. Blunt dissection through the parotid gland done with a hemostat parallel to the anticipated direction of the facial nerve. The tough parotid septa was then divided. When branches of the facial nerve were encountered, usually at least $5.0 \mathrm{~mm}$ deep to the parotid fascia, they were retracted anteriorly. Masseter muscle was exposed, dissection carried out posteriorly, pterygomasseteric sling incised. Subsequently, a subperiosteal dissection was carried out till the sigmoid notch and the fracture site exposed. Fracture was then reduced by applying traction on the mandibular angle and pulling it down. When reduction was achieved, the condyle was fixed with using Delta titanium condylar plate and four monocorticalscrews (Figure 6). Occlusion and joint mobility was checked. The surgical field was then irrigated \& inspected, followed by meticulous hemostasis. The pterygomasseteric sling was reconstructed using 3-0 vicryl sutures. Branches of facial nerve carefully inspected. The parotid fascia and SMAS were repaired to attain a watertight closure using 3-0 vicryl to prevent salivary fistula. Subcutaneous sutures were placed using 4-0 vicryl/polygalactine. The skin was closed with interrupted sutures using 4-0 or 5-polypropylene suture. Pressure dressing was given which was left in place for 48 hours.

Patients were evaluated clinically and radiologically for the following parameters:

1. Surgical access graded excellent, good \& fair

2. Duration of surgery

3. Anatomic reduction assessment with relevant radiographs

Evaluation was done by comparing the pre \& post operative radiographs and was graded as

- Anatomically correct: Correct open reduction

- Good: Shortening less than $2.0 \mathrm{~mm}$

- Satisfactory: Shortening less than $5.0 \mathrm{~mm}$

- Poor: Values above those mentioned

4. Occlusal discrepancies: The changes in occlusion were noted. This was assessed clinically by inspecting abraded surfaces of the teeth, as well as subjectively by the patients.

5. Need for post operative IMF

6. Facial nerve morbidity: Facial nerve injury was deemed to have occurred if the patient was unable to draw the lower lip and corner of the mouth downward, was unable to whistle, or was unable to completely close the eyelids or wrinkle the brow.

7. Sialocele, salivary fistula etc

8. Hematoma

9. Mouth opening: Inter incisal clearance was measured with a willis gauge

10. Auricular anaesthesia: To evaluate post operative function of the greater auricular nerve, the sensory reaction of the external ear was investigated by means of a pinprick test.

11. TMJ symptoms like joint pain, deviation of the mandible on opening etc.

Deviation of the mandible was assessed by the surgeon clinically. Pain was perceived by the patient. Severity of the pain was assessed using a visual analogue scale which was given to patients as printed proforma during follow up days: 
Visual analogue scale: score $(0-10)$

No pain $\begin{array}{llllllllllll}0 & 1 & 2 & 3 & 4 & 5 & 6 & 7 & 8 & 9 & 10\end{array}$

12. Plate Infection, plate fracture etc

13. Scar: Patients were reviewed at regular intervals and the character of the scar was assessed by both the patient $\&$ the surgeon clinically. The character of the scar was graded as: inconspicous, conspicous, hypertrophic.

The data collected were subjected to statistical methods comprising of Descriptive statistics, Cross Tabs, and Pairedsamples $t$ test \& Chi-Square Test. SPSS (Statistical presentation system software) for windows Version-16 was employed for statistical analysis.

\section{Results:-}

\section{Age distribution:-}

In the study they were totally 20 pts in number, we noted 9 cases(45\%)in the age group of $18-25 \mathrm{yrs}, 9(45 \%)$ cases in age group of 26-35 yrs and noted 2 cases (10\%) in the age group of 36-55 yrs. Mean age being 28.7 in male and 33.8 in female. Cramer's V value for the age and sex distribution found to be 0.310 which is 0.382 significant .

\section{Sex distribution:}

In 20 patients, they were $15(75 \%)$ male pts and $5(25 \%)$ female pt.

\section{Mechanism of injury:}

$5(25 \%)$ pts sustained the injury due to road traffic accidents. $15(75 \%)$ cases sustained injury due to self fall. Chi square value found to be 5.000 at a $\mathrm{P}$ value of 0.025 .

\section{Type of condylar fracture:}

11 cases (55\%) sustained Type II fracture and 9 cases (45\%) sustained Type III fracture. Chi square value found to be 0.200 at a $P$ value of 0.655 .

\section{Associated fractures:}

There was $1(5 \%)$ case isolated condylar fracture, parasymphysis fracture was noted in 8 cases $(40 \%)$ \&symphysis fracture in 7 cases (35\%), body fracture in 4 cases $(20 \%)$. Chi square value found to be 5.000 at a $\mathrm{P}$ value of 0.025 .

\section{Side of the fracture:}

In 20 pts, 9 cases (45\%) sustained unilateral fracture of condyle \& 11 cases $(55 \%)$ sustained bilateral fracture of condyle.Chi square value found to be 4.900 at a $P$ value of 0.086 .

\section{Duration of surgery:}

Duration of surgery was found to be $\mathrm{min}$ of $40 \mathrm{~min}-65 \mathrm{~min}$ with a mean of $52.95 \mathrm{~min}$.

\section{Surgical access:}

Access was rated as excellent, good \& fair. In this study excellent access was achieved in 14 cases (70\%), access was good in 5 cases $(25 \%) \&$ fair in 1 case $(5 \%)$. Chi square value found to be 13.300 at a $P$ value 0.001 .

\section{Plating:}

In 11 bilateral condylar fracture, only 1 patient $(9.9 \%)$ was plated on both sides with the delta condylar plate.

\section{Anatomic reduction:}

Anatomic reduction was rated as anatomically correct, good \& satisfactory with the help of postoperative radiographs. In this study anatomically correct reduction was achieved in 10 cases (50\%). Good reduction was achieved in 8 cases (40\%) and satisfactory in $2(10 \%)$ cases. Chi square value found to be 5.200 at a P value .074 .

\section{Post operative occlusion:}

Postoperative occlusion was rated as deranged or normal. A normal occlusion was achieved in 17(85\%) cases ,occlusion was found to be deranged in 3 cases (15\%). Cramer's V value for post operative occlusion is 0.860 at $\mathrm{P}=0.00$, which is statistically significant. 


\section{Need for intermaxillary fixation postoperatively:}

There was no need for post operative IMF in 3 cases (15\%) Postoperative IMF was required in 17 cases (85\%). Cramer's V value found to be 0.285 at a $\mathrm{P}$ value 0.072 .

\section{Post operative mouth opening:}

The mean mouth opening pre op was 21.05 and post op was 44.85 . The paired sample test was found to be 23.80000 at $\mathrm{P}=0.000$, which is statistically significant.

\section{Complications encountered:}

We encountered two types of complications postoperatively namely wound infection in 5 cases $(25 \%)$ and sialocele in 3 cases $(15 \%)$. Chi square value found to be 22.000 at a $\mathrm{P}$ value 0.000 , which is statistically significant.

\section{TMJ Dysfunction:}

We encountered two types of TMJ dysfunction in this study i.e., ipsilateral deviation on opening the mouth and pain on opening the mouth which was assessed subjectively by the patient \& was given a VAS score ranging from 1-10 depending on the severity. In this study, ipsilateral deviation of the mandible was noted in 2 case (10\%). Mild pain with a vas score of 2 was reported in 2 cases $(10 \%)$, score 3 and 2 in 1 patient $(9.1 \%)$. Chi square value found to be 15.700 at a $P$ value 0.000 , which is statistically significant.

\section{Post Operative Scar:}

Scar was assessed clinically \& was graded as conspicuous, inconspicuous or hypertrophic. In this study after a period of six months all 20 patients (100\%) had an inconspicuous scar which was well camouflaged (Figure 5). Cramer's V value found to be 1.000 at a P value 0.000 , which is statistically significant.

\section{Discussion:-}

Mandibular fractures are frequent in facial trauma and about $30 \%$ involve the condyle.(De Riu et al, 2001.) The best treatment strategy, that is, closed or open reduction and internal fixation, remains controversial (Santler et al, 1999). Closed treatment has been the preferred treatment for several years, however longterm complications include open bite, pain, inadequate restoration of vertical height of the ramus, arthritis, and deviation of the mandible (Singh et al, 2012).

The open reduction and rigid internal fixation allows for good anatomic repositioning, restoration of the ramal length, avoidance of long term sequel like clicking and late arthritic changes and an earlier return to normal function without the need for inter maxillary fixation. Because of this early return to function, the chances for ankylosis is greatly reduced. Due to all these reasons and advantages there is an increase in the interest among majority of the surgeons to manage condylar fracture by ORIF[11].

In 1925 Silverman described the first method of ORIF of the condyle by an intraoral route, principally for low subcondylar fractures. Since then several techniques have evolved. Koberg and Momma described the retromandibular approach for plate and screw fixation whereas Petze and then Eckelt in the early $1980^{\mathrm{s}}$ described methods of fixation with lag screws by a submandibular approach. Kitayama described a method for the intraoral placement of a lag screw[12].

Multiple approaches have been proposed and used in order to visualize and reduce condylar fractures which include the intra oral, coronal, preauricular, face-lift (Rhytidectomy), post auricular, endural, endoscopic, retromandibular, and submandibular and often in combination. Potential damage to facial nerve and its branches with some approaches and possibility of post operative scar have drastically affected the choice of surgical approach. Retromandibular approach deserves special attention as it is ideally suited to the technique of miniplate osteosynthesis in the area of difficult access. This approach seems to give the benefits of the good cosmetic and a adequate exposure for manipulation and reduction of the fracture and for placement of fixation.

The mini retromandibular approach is a conservative modification of the retromandibular approach mentioned in literature, in that the incision proposed is only $2 \mathrm{~cm}$ long as opposed to the classical incision of 2.5-3cm[13]. The advantages of the approach is the subcutaneous dissection allows the extension of the surgical wound to the level of the fracture. In all phases, the surgery performed is perpendicular to the fracture which facilitate the reduction of medially displace proximal stumps which are generally very hard to manage in other approaches. The articular 
capsule is never breached which is a major post operative function advantage[14].In our study of 20 patients, there was high male predominance $(75 \%)$ to female $(25 \%)$, with a $\mathrm{P}$ value of 0.007 which is significant, which can be correlated to the study of Marker et al(2000) out of 348 pts, 230 were men and118 were women[3].

The high percentage of the patients were found in age group of 26-35(45\%), mean age is 28.7 in male and 33.8 in female, which is similar to the study of Marker et al(2000). It can be seen that in men there is a concentration of fractures in the second and third decades[3].

Road traffic accidents and self fall accounted for the majority of patients. This finding is in agreement with the studies done by several authors . In our study, out of 20 pts 5 cases of RTA (25\%), 15 cases of self fall (75\%) were noted. In a study conducted by Newman et al(1998) the most common cause of condylar fracture was cited as RTA(33\%), and fall(52\%)[12].In a study conducted by Pereira Max et al (1995)which stated that the majority of fractures were the result of car accidents (five cases), fall from a bicycle (five cases),falling down (three) and physical aggression (two).[15]

In our study out of $20,9(45 \%)$ cases were unilateral fractures of the condyle \& $11(55 \%)$ cases were bilateral fractures. In the series of studies conducted by Marker et al (2000)[3] He reported that of the total sample size of 444,252 of unilateral and 192 bilateral[3] \&out of 45, 30(67\%) had a unilateral fracture of mandibular condyle \& $15(33) \%$ sustained bilateral fracture of the condyle[16].

When considering the associated injuries fracture of parasymphysis(40\%)and fracture of the symphysis(35\%) and fracture of body $4(20 \%)$ was the most common associated fractures. Isolated condylar fracture is seen in $1(5 \%)$ patient. In a study conducted by Hyde et al(2002), showed that it was associated invariably with parasymphysis[20] and study conducted by Marker et al(2000), showed that fracture of the symphysis was the most common(79\%)[3].

The type of fractures were classified according to Spissel\&Schroll (1972)[17] . Out of 20 patients, 11 patients sustained Type II fracture (55\%), 9 cases were classified as Type III (45\%)which was similar to the study conducted by Schneider et al(2007), where out of 45 condylar fractures, 36 fractures were type II, 3 patients sustained type III fracture \& 7 cases were type IV fractures.[18]

The duration of surgery varied from minimum of 40 min to maximum of 65 min (mean= $52.95 \mathrm{~min}$ ). This is more in relation to operative time taken by Federico Biglioli et al(2008)[19], according to which mean operating is 32 $\mathrm{min} /$ condyle. Time taken to complete the dissection also was dependent on the amount of fracture displacement and the type of patient. In our study the additional time was required for the placement of the Delta titanium condylar plate.

Access was rated as excellent, good and fair. In this study excellent access was achieved in 14 cases (70\%), access was good in 5 cases (25\%) \& fair in 1 cases (5\%), this is consistent with study conducted by S. Shah et al which states that this approach provides adequate exposure and reduction, minimum nerve injury and minimum scarring[16].

The anatomic reduction was graded as Anatomically correct, Good, Satisfactory and Poor according to Hochban et al(1996)[21] and in our study $10(50 \%)$ cases were anatomically correct, 8(40\%) cases were Good, 2(10\%) cases were satisfactory(Figure 3).

In a study conducted by MaciejSikora et al, (2016) which showed that the delta titanium condylar plate were able to provide stable osteosynthesis to condylar fractures with practically no risk of breaking of the plate and failure in form of the loosening of the retaining screws and does not causes any significant disturbances in the fracture healing process. The primary stability achieved by delta titanium condylar plate was superior to that obtained by single plating techniques.

A prospective study conducted by Kumaran S et al, for analysis of two different surgical approaches preauricular and mini retromandibular approach for mandibular condylar fractures. He summarizes the mini retromandibular approach is extremely easy and fast to perform and carries low risk of damaging the facial nerve whilst leaving a barely noticeable scar. 
When considering the occlusal discrepancies, the occlusion was deranged in all the 20 cases preoperatively which was also an indication of ORIF. Postoperatively occlusion was achieved in 17 cases (85\%). Occlusion was found to be derranged in 3 cases $(15 \%)$.

In a study conducted by Marker et al (2000), it was observed that the occlusal disharmony was associated other fractures of mandible involved[3]. However in our study all the cases with post operativeocclusal derangement was managed with post operative IMF with elastics for a period of one to two weeks which corrected the problem. There was no need for post operative IMF in 3 cases (15\%) Postoperative IMF was required in 17 cases (85\%).

A study conducted by Widmark et al (1996) showed that postoperatively, in one third all male patients (six unilateral fractures and one bilateral fracture), IMF was used. A tendency to occlusal disturbance was seen in these patients at the end of the operation, after plating the fracture, as it was doubtful whether they could cooperate and follow the postoperative instructions for a soft-food diet and avoidance of violent physical contact with others[8]. Several authors,[3][8][22] have combined miniplateosteosynthesis with intermaxillary fixation. Zide.F.M et al (1983)[23] used IMF for 6 weeks after fixation of condylar fracture with wires using the rhytidectomy approach.

The mean post operative mouth opening is $44.85 \mathrm{~mm}(40-50 \mathrm{~mm})$ with a $\mathrm{P}$ value of 0.000 which is statically significant. Similar studies done by various authors on mouth opening were observed as Zide and Kent et al(1983)[23]:45 mm, Perira et al (1995:35-50mm (41.9mm)[15], Widmark et al (1996)[8]:40-67mm (51 mm), Schon et al(2002)[24]: $\geq 40 \mathrm{~mm}$.

We encountered some postoperative complications like infection at surgical site (25\%) in 5 cases \&sialocele (15\%) in 3 case, with a $P$ value of 0.000 which is statistically significant. We didn't encounter any facial nerve palsy as the dissection was done through masseter reflecting parotid anteriorly this in consistent with the study done by Wilson et al (2005)[14] which showed that the area next to the anterior edge of the parotid gland is usually relatively free of branches of the facial nerve, making this an ideal point to dissect down to the fracture if a buccal branch crosses the field it is easily retracted up or down.

The infection resolved during the course of 10 day per oral antibiotics and sialocele got resolved spontaneously in a period of 3-5weeks which the pressure dressings. We encountered two types of TMJ dysfunction in this study i.e, ipsilateral deviation on opening the mouth and pain on opening the mouth which was assessed subjectively by the patient using and was given a VAS score ranging from 1-10 depending on the severity.

There were two cases of pain which were scored as VAS- 2(10\%) \& VAS-3(5\%) and 2 case of ipsilateral deviation $(10 \%)$ on opening mouth, with a $\mathrm{P}$ value of 0.000 which is statistically significant. Ipsilateral deviation progressively decreased and disappeared in 2-3 months period, patients were advised mirror exercises.

Patients who complained of pain were treated symptomatically \&was resolved completely in a period of 1-2 months. Practically the problems of pain and hypomobility may complicate both open and closed reduction. The physiotherapy was goal oriented until an opening mouth with full range of excrusion and will prevent some late complications like ankylosis and post traumatic functional abnormalities Yasuharu et al(1990)[22].

In study conducted by Widmark et al(1996) which showed $2 \mathrm{~mm}$ deviation to the operated side on mouth opening[8]. In study conducted by Hyde et al(2002) out of 25 pts 12 pts had mandibular deviation on opening mouth was noted[20]. In as study done by Vesnaver et al(2005) 7(21\%) pts had deflection had deflection, 4(12\%) to the same side and $3(9 \%)$ to the contralateral side[25].

Scar was assessed clinically \& was graded as conspicuous, inconspicuous or hypertrophic. In this study after a period of 6 months, all 20 patients (100\%) had inconspicuous scar which was well camouflaged.

The principles behind open reduction and internal fixation with miniplateosteosynthesis is "functionally stable osteosynthesis" as proposed by Champy et al (1975) and Champy and Lodde (1976). Champy determined the ideal line of in the region of mandibular body but no such lines was proposed in the region of condyle because of limited data. Meyer et al (2002) attempted to fill this void to determine the ideal line of osteosynthesis in the region of condyle. During biting forces in the region of molars, strain lines were detected in the condylar region. 4 hole 
miniplate parallel to the condylar axis was found to provide compression osteosynthesis and similar plates in the region parallel to mandibular notch provide dynamic osteosynthesis.

Hence, adaption of single 4 hole miniplate, as was initially proposed did not provide dynamic osteosynthesis and resulted in fracture of the plating during function.. 2 plate fixation (1 miniplate parallel to condylar axis and second miniplate parallel to mandibular notch ) met with the fulfilment of dynamic osteosynthesis. Single plate parallel to condylar axis if used as fracture reduction and second plate parallel to mandibular notch provides dynamic osteosynthesis. But adaptation of two miniplates in the region of condylar axis is difficult due to constriction of condylar neck.

In our study, the delta condylar plate stabilize the condylar fracture as one side is parallel to the sigmoid notch and other side comes parallel to the posterior border which results in good anatomic reduction of fracture with minimal complications. The only disadvantage of being slight difficulty in fixing of the plate. Due to its shape, neutralization of changing strains at the anterior, lateral, and posterior borders in condylar neck region is noticed which lead to stability of the fractured fragment[26].

Among the approaches to condyle, miniretromandibular approach is easy and fast to perform, presents a very low risk of the facial nerve and leaves a barely noticeable scar in a relatively hidden region. The other advantages is of shorter working distance from the skin incisions to the condyle which provides greater access to the posterior border of the mandible and the sigmoid notch.

\section{Conclusion:-}

Facial injuries are most commonly associated with falls, motor vehicle accidents, sports-related trauma, and interpersonal violence. The temporomandibular region is certainly not exempt from injury related to these factors. The treatment of injuries to the temporomandibular joint (TMJ) and its surrounding region is one of the more controversial areas in management of facial trauma.

A variety of fixation methods are available like plating, lag screw fixation, transosseus wiring, pin fixation techniques and external fixators. Bone plating through a preauricular, submandibular, or retromandibular approaches are the most commonly employed techniques.

Mini Retromandibular approach is easier and faster to perform and carries low risk of damaging the facial nerve whilst leaving a barely noticeable scar. In considering the anatomic reduction of the fracture, posterior border of the mandible can be visualized throughout the surgery.

Using the Delta condylar plate for condylar fractures has 3 main advantages: 1 ) neutralization of changing strains at the anterior, lateral, and posterior borders; 2) the additional stabilization provided by a compression miniplate; and 3) a small, manageable osteosyntesis plate. The new design of Delta Trilocking plate has the gliding holes which help to compress the fracture through screw adjustments, which accelerate bone healing.

On the basis of these clinical results as well as the degree of patient satisfaction, it may be concluded that surgical treatment of the fractured, displaced or undisplaced condyle using the Mini retromandibular approach with anatomic reduction using Delta condylar plates are excellent. 


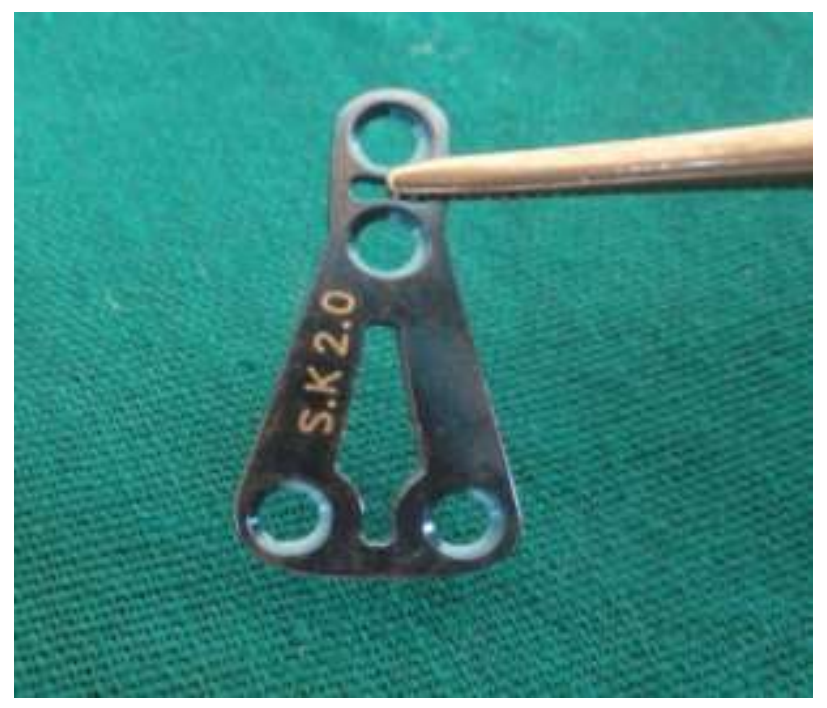

Figure 1:-Delta condylar plate

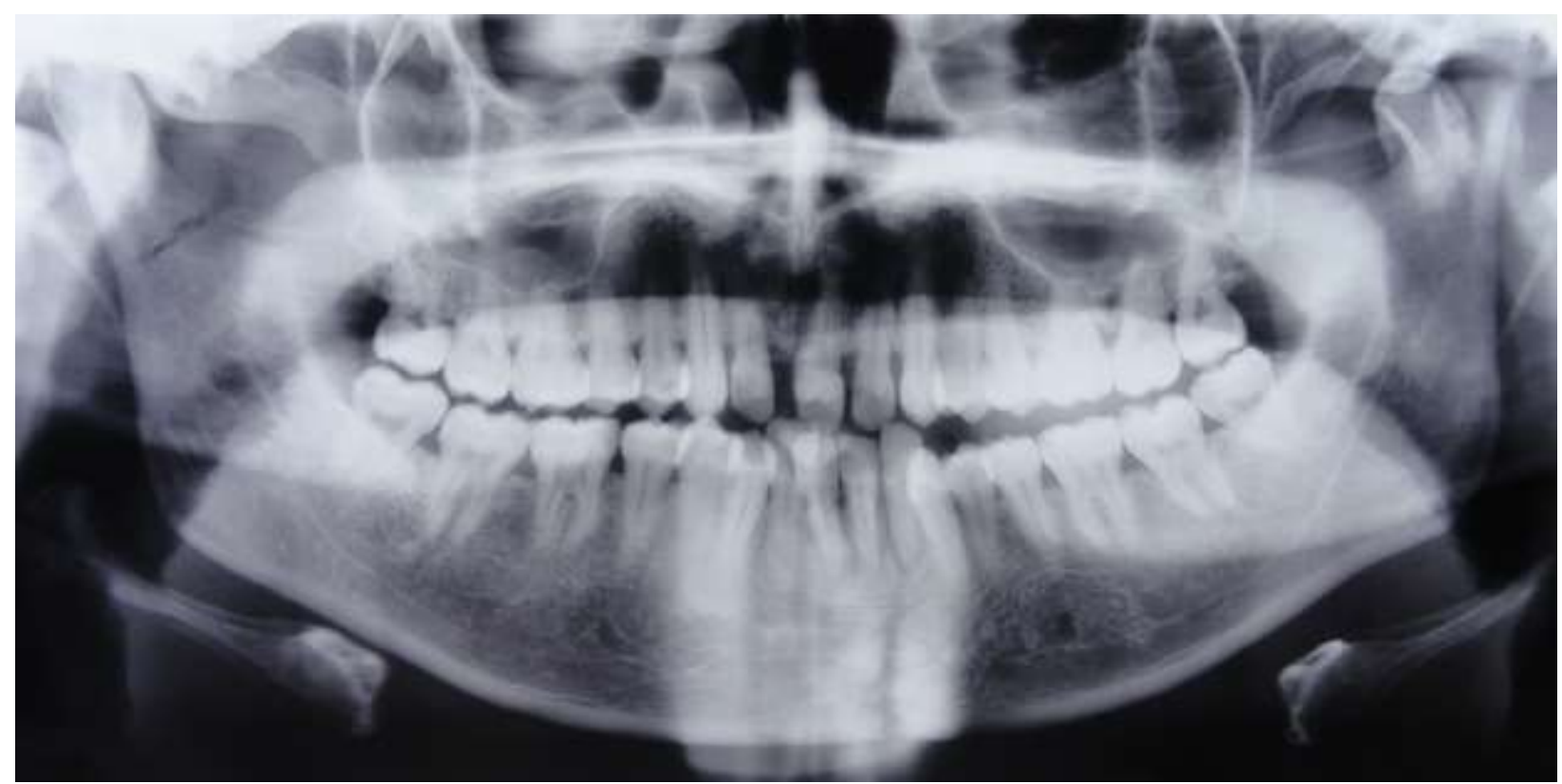

Figure 2:-Pre operative OPG X-ray. 


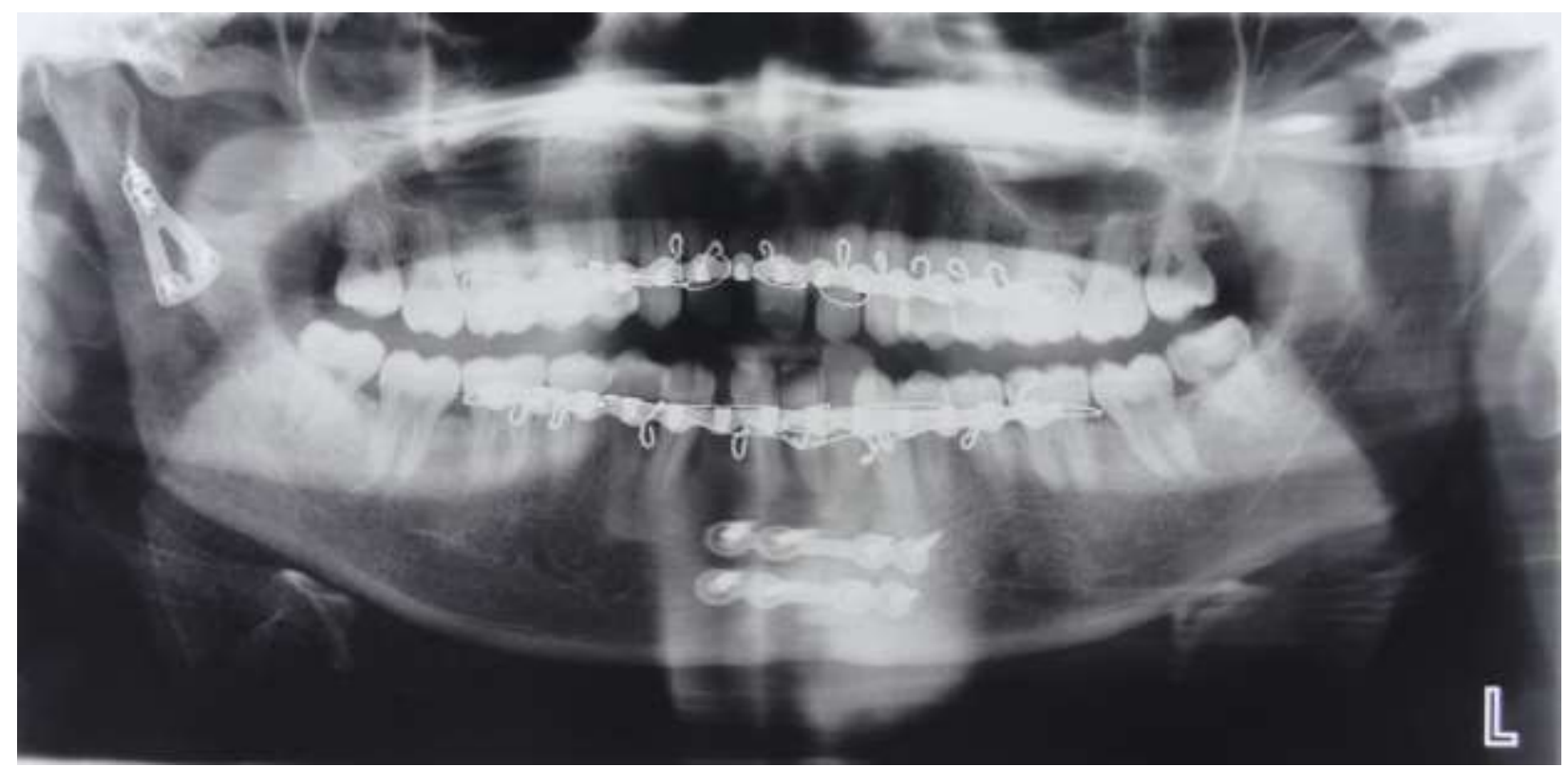

Figure 3:-Post operative OPG X-ray

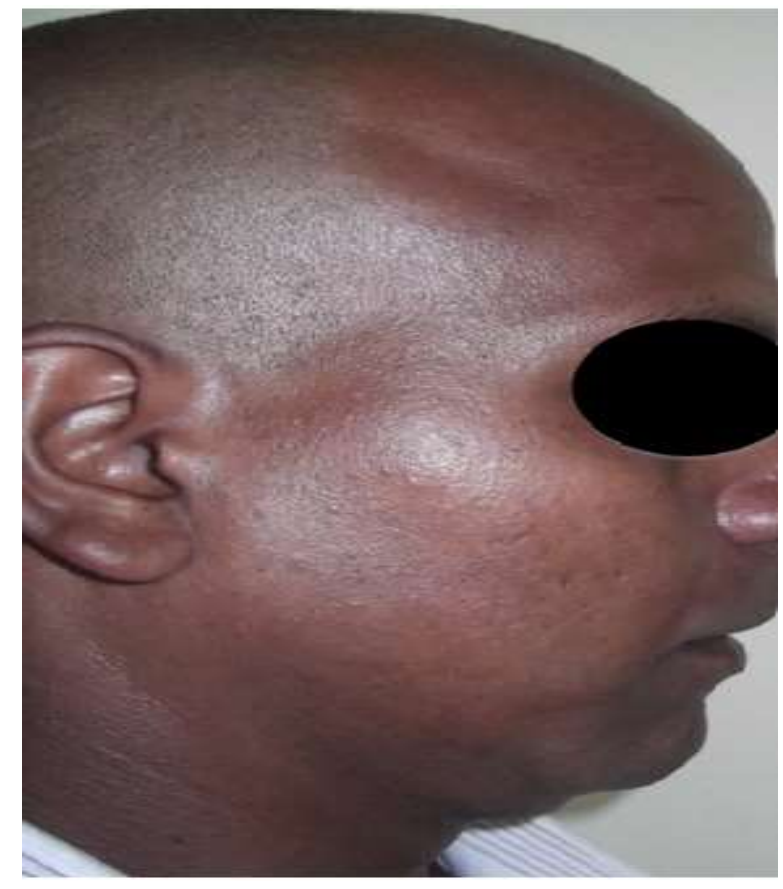

Figure 4:-Pre operative profile view 


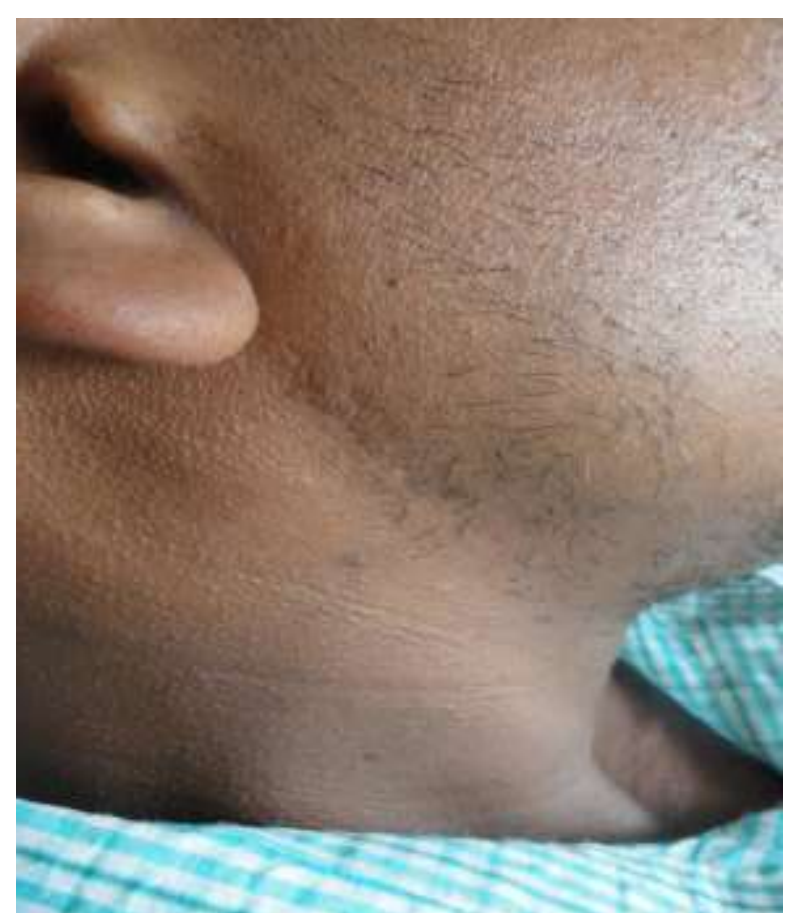

Figure 5:-Post operative profile view after 6 months

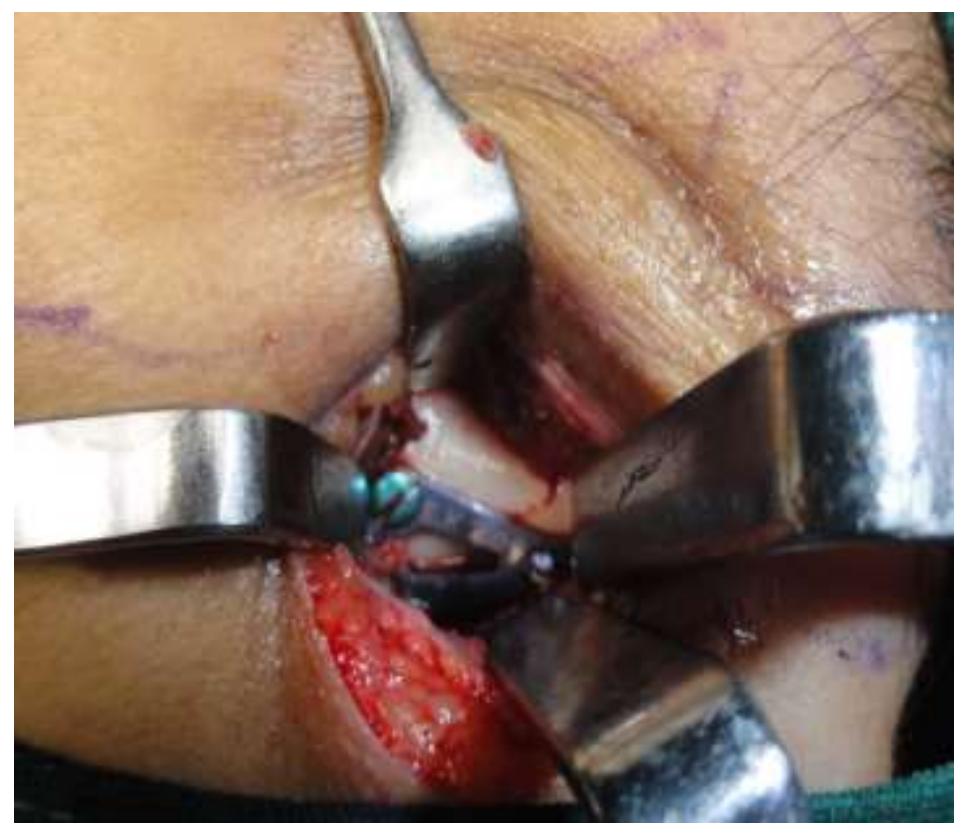

Figure 6:-Intra operative Delta plate

\section{References:-}

1. Parameters of Care: Clinical Practice Guidelines for Oral and Maxillofacial Surgery (AAOMS ParCare 2012) J Oral MaxillofacSurg ;70:e162-e203

2. Dr. Narendra N. Hirani, Dr. NishantPujara. Comparison of Open Reduction and Internal Fixation in Case of Symphysis and Parasymphysis Mandible Fracture. International Journal of Science and Research (IJSR), June 2015; Volume 4 Issue 6

3. P.Marker, A.Nielson,H.Lehmann Bastian. Fractures of the mandibular condyle.Part 1:Patterns of distribution of types and causes of fractures in 348 patients. British journal of Oral \& Maxillofacial surgery, 2000;38:417-421. 
4. Fonseca R.J, and Robert V. Walter. "Oral and maxillofacial trauma” Pennsylvania; W.B.Saunders company; 2005;3(1):524.

5. UweEckelt,MatthiasSchneider,Francois Erasmus et al. Open versus closed treatment of fractures of the mandibular condylar process-A prospective randomized multi-centre study, Journal of cranio-maxillofacial surgery 2006;34:306-314.

6. Chossegros.C, Cheynet.F, Blanc.J, Bourezak.Z. Short retromandibular approach of subcondylar fractures. Oral Surg Oral Med Oral Pathol Oral RadiolEndod. 1996;82:248-52.

7. Maria Cecilia Closs Ono, GilvaniAzor de Oliveirae Cruz, Renato da Silva Freitas. Mini retromandibulartransparotid approach for extracapsular condylar fractures of the mandible. Brazilian Journal of Plastic Surgery. 2013;28(3):428-33.

8. G.Widmark, T.Bagenholm, K.E.Kahnberg,et al. Open reduction of subcondylar fractures. A study of functional rehabilitation. Int. J. Oral MaxillofacSurg; 1996;25:107-111.

9. ManojChaudhary, Harshvardhan pant, Manpreet Singh, ArpitVashistha, Gagandeepkaur. Evaluation of trapezoidal-shaped 3-D plates for internal fixation of mandibular subcondylar fractures in adults. Journal of Oral Biology and Craniofacial Research 5 (2015), I34-I39.

10. MaciejSikora, MarcinSielski, AgataStapor, DariuszChlubek, Use of the Delta plate for surgical treatment of patients with condylar fractures. Journal of Cranio-Maxillo-Facial Surgery 43(2015)1961-1965.

11. A.P. Mohan et al. Comparison of preauricular approach versus retromandibular approach in management of condylar fractures. J Maxillofacial oral surg 2012;11(4):435-441.

12. Newman.L. A clinical evaluation of the long-term outcome of patients treated for bilateral fracture of the mandibular condyles, British journal of oral and maxillofacial surgery 1998;36:176-179.

13. Kumaran S, Thambiah LJ. Analysis of two different surgical approaches for fractures of the mandibular condyle. Indian Journal of Dental Research, 23(4), 2012;23:463-468

14. Wilson.A.W, Ethunandan.M, Brennan.P.A. Transmassetericantero-parotid approach for open reduction and internal fixation of condylar fractures. British journal of oral and maxillofacial surgery 2005;43:57-60.

15. Pereira M. D Marques, A, Ishizuka M ,. Keira S M, Brenda E, Wolosker A B. Surgical treatment of the fractured and dislocated condylar process of the mandible. . Journal of Cranio-Maxillofacial Surgery 1995;23:369-376.

16. S. Shah,S. Ali,AMirza: RetroparotidTransmasseteric Approach to condylar fracture through Miniretromandibular access;AAOMS;2011;session 4;e-37

17. Gunter Lauer, Winnie Pradel, Matthias Schneider, UweEckelt, A new 3-Dimensional plate for transoral endoscopic-assisted osteosynthesis of condylar neck fractures. Journal of Oral Maxillofacial Surgery (2007) 65:964-971

18. Schneider.M,Lauer.G,Ecklet.U. Surgical treatment of fractures of the mandibular condyle: A comparison of long term results following different approaches -Functional, axiographical, and radiological findings. Journal of Cranio-Maxillofacial Surgery 2007; 35:151-160.

19. Federico Biglioli, GiacomoColletti. Mini - retromandibular approach to condylar fractures. Journal of CranioMaxillofacial Surgery (2008) 36, 378-383

20. Hyde.M, Manisali.M, Aghabeigi.B, Sneddon.K, Newman.L. The role of open reduction and internal fixation in unilateral fractures of the mandibular condyle: A prospective study. British Journal of Oral and Maxillofacial Surgery 2002; 40:19-22.

21. Devlin M. F, Hislop W. S, Carton A. T. M. Open reduction and internal fixation of fractured mandibular condyles by a retromandibular approach: surgical morbidity and informed consent. British journal of oral and maxillofacial surgery.2002;40:23-25.

22. Takenoshita.Y, Ishibashi.H, Oka.M, Comparison of functional recovery after non-surgical \& surgical treatment of unilateral dislocated low subcondylar fractures. J Oral Maxillofac Surg.1990; 48:1191-1195.

23. Zide.M.F, Kent.J.N.Indications for open reduction of mandibular condyle fractures, J.Oral\&MaxillofacSurg 1983;41:89-98.

24. Schon.R, Gutwald.R.,Schramm.A, Gellrich.N.C, Schmelzeisen. R. Endoscopy assisted open treatment of condylar fractures of the mandible:extra oral vs intraoral approach. . J. Oral Maxillofac Surg. 2002;31:237-243.

25. Vesnaver.A, Gorjanc.A, Eberlinc.A, .Dovsak. Akansky.A.A. The periauriculartransparotid approach for open reduction and internal fixation of condylar fractures. Journal of cranio-maxillofacial surgery, 2005:33,169-179.

26. ShaileshNareshkumarKokal, SurajArjunAhuja, Nareshkumar $T$ Kokal, Haemant A Baonerkar. Clinical experience with osteosynthesis of subcondylar fractures of the mandible using Delta plate. Journal of Contemporary Dentistry, January-April (2016);6(1):63-66 